\title{
Exploring Elder Consumers' Interactions With Information Technology
}

Michelle G. Hough, (E-mail: mghough@psu.edu), Pennsylvania State University

\begin{abstract}
Advances in health care are enabling the population of the United States to live longer. Use of information technology can improve the quality of life for the elderly, yet many older consumers have limited interactions with information technology and so may be denied its potential benefits for enhancing quality of life. This study explores older peoples' current interactions with information technology, details personal and technological factors which may impact engagement, and discusses the resulting sociological and commercial implications for encouraging the elderly to embrace information technology toward enhancing quality of life.
\end{abstract}

\section{Introduction}

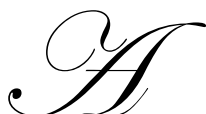

dvances in nutrition and health care have led to the population of the United States aging rapidly. Titus (1982) notes, "In general, the advances in medical knowledge and technology have contributed, and will continue to contribute, to the prolongation of life. Citizens today may expect to be healthier and to live longer than previous generations" (p. 12). For the purpose of this study, senior citizens, older people, and other related terms will refer to individuals at least 65 years of age. Coughlin (1999) indicates, "Although chronological age is an imperfect measure of what is 'old,' 65 is the traditional milepost of senior adulthood" (p. 53). Longino (1994) charts the startling increases in the population and percentage of older Americans related to these advances, noting that there were 3.1 million Americans, or 4 percent of the total population, aged 65 and older at the beginning of the $20^{\text {th }}$ century. A significant increase was visible as early as the 1930 census and by 1960 , there were 16.7 million older Americans comprising 9 percent of the population. By 1990, the elderly population almost doubled again; totaling 31 million people, or 12 percent of the population. The Census Bureau projects that 62 million Americans, almost 20 percent of the population, will be aged 65 and older by 2025 . Further, the percent of oldest Americans, those aged 85 and older, is increasing at an even faster rate than the total elderly population. By 2025, the oldest old will comprise 20 percent of the elderly, up from less than 10 percent in 1990.

In contrast, the number of potential caregivers for this rapidly expanding older population will significantly decrease. Longino notes that today's elderly are well-endowed with family resources since they are the parents of the baby boom. But this supply of family caregivers will decrease as the baby-boomers themselves begin to retire, and the decrease is aggravated by the trend of the baby-boomers to have fewer children than their parents.

Ensuring the quality of their golden years is of utmost importance to the elderly, their caregivers, and to society in general. Information technology is one important mechanism in meeting the needs of a growing elder population with a decreasing number of caregivers. Pew (2001) notes that seniors who have Internet access benefit greatly by using it to communicate with family, research health information, and track investments. Brink (1997) finds that with the growing dependency rate, technology can ensure that the quality of care does not decline due to the numerical imbalance between generations. She explains that when applied to products and services, both traditional industrial technology, described as mechanical devices that enhance physical capabilities, and information technology, described as electronic devices that extend the potential of the human brain, can be of value in enabling older people to participate in the workplace, marketplace, and society in ways never before considered possible. However, Brink cautions that effective use of technology requires an informed, astute, literate consumer. 
Although younger generations have grown to adulthood in the Information Age, many older consumers have had only limited exposure to information technology. One potential area of underexposure occurs with respect to personal computing and the Internet. Pew (2001, p.2) notes, "Senior citizens comprise $13 \%$ of the U.S. population, but just $4 \%$ of the U.S. Internet population." Pew further find that although older people who access the Internet benefit from its resources, most seniors do not use computers, do not intend to go online, and do not believe they are missing out on anything. Many seniors engage with life using lower technology mechanisms such as reading newspapers or watching television even though these technologies do not offer the breadth and depth of quality of life information available to those utilizing higher technologies.

As such, it may be that a significant number of older people are not informed, astute, and literate consumers with respect to information technology and so could be denied many potential benefits related to enhancing quality of life. This paper will assess current connections between senior citizens and information technology by examining several related works, some which quantify and qualify elder user interactions with information technology, and others which attempt to detail personal and technical factors which may impact potential engagement. After assessing the current state of interaction, this work will discuss the resulting sociological and commercial implications with respect to enabling older people to utilize information technology toward improving quality of life.

\section{Literature Review}

\section{Quantifying and qualifying interactions}

The Pew Internet and American Life project is a non-profit initiative that explores the impact of the Internet on various facets of society through comprehensive and impartial academic-quality research (www.pewinternet.org). Their 2001 exploratory report, "Wired Seniors," concluded that senior citizens comprise only 4 percent of the Internet population as compared to comprising 13 percent of the general population. Further, Pew 2001 found that although 15 percent of senior citizens access the Internet, a full 56 percent of elderly Americans do not use computers and do not plan to go online. The small percent of older people using the Internet are typically male, married, highly educated, enjoy relatively high retirement incomes, and are first coaxed online by relatives. The online activities of these seniors mirror those of the general population and include using email ( 93 percent), seeking information on hobbies (58 percent), reading news (55 percent), searching for health and financial information (53 and 44 percent respectively), and playing games ( 32 percent). Once engaged, these seniors feel they benefit greatly from their online activities, both in terms of familial relationships and access to resources, and 68 percent indicate they would miss the Internet if they lost their access.

Hough (2002) conducted a study to quantify elder consumers' interactions with technology, determine the applications most frequently used, and assess the group's awareness and concern of potential privacy issues related to information technology. Study participants were predominantly female (71 percent) with a high school education or less (89 percent) and overwhelmingly did not use computers on a regular basis ( 80 percent). The minority who did use computers used them primarily for one or more of the following purposes: playing games ( 9 percent), electronic mail ( 7 percent), and information gathering ( 7 percent). Although computer use was not popular, $60 \%$ of participants indicated they do use some type of technology. The most common technology uses noted were credit cards (55 percent), shopper affinity cards (47 percent), and automatic teller machines ( 20 percent). These senior citizens displayed moderate levels of awareness and somewhat greater levels of concern regarding unauthorized access of items of personal information. Hough also found that awareness could be increased using a relatively simple educational intervention.

The 2003 Pew study, "Consumption of Information Goods and Services" sorted Americans into eight distinct groups with respect to information technology. Pertinent to this study are two groups: the small cluster of "wired senior men" comprising one percent of the sample and the "low tech elderly" comprising 16 percent of the sample. The "wired senior men" are male, average age of 70, highly educated, and use the Internet for information gathering and some online transactions, while the "low tech elderly" are primarily female, average age of 73, who typically avoid the Internet choosing to interact instead with lower technologies such as telephones, television, and 
newspapers. Mann (1997) echoes this, noting that although advanced telecommunications technologies like the Internet offer exciting opportunities for older people, including those with disabilities, the overwhelming majority still rely primarily on their telephone to fulfill their telecommunication needs.

Pew's 2004 follow-up study, "Older Americans and the Internet" indicates that while the number of older Americans accessing the Internet has increased to 22 percent of those aged 65 and older, up from the 15 percent cited in their 2001 study, older consumers still lag far behind other age groups in embracing this technology. By contrast, 58 percent of these older consumers' closest peer group, the so-called "silver tsunami", aged 50 to 64, access the Internet. These numbers are echoed in computer usage not necessarily related to the Internet. Pew found that only 29 percent of older consumers use a computer on even an occasional basis, and 80 percent of off-line older consumers do not ever intend to go on-line, or even spend the time and money to learn to use a computer.

These studies, taken as a whole, portray a senior population generally indifferent to engaging with higher information technologies such as personal computers and the Internet, and only moderately aware of potential issues related to unauthorized access of their personal information. The majority of older people are comfortable interacting with traditional technologies such as telephone, television, newspapers, credit, debit, and affinity cards. The small percent of senior citizens who choose to interact with higher technologies typically are initially influenced to engage by relatives, but later grow to appreciate the resources available through their access.

\section{Personal and technological factors impacting engagement}

Clearly, given the reticence of many older people to interact with new information technologies, consideration should be given to assessing personal and technological factors which can positively or negatively impact the engagement experience. Trocchia and Swinder (2000) identify six themes useful in illustrating differences between elderly Internet users and non-users. Users and non-users were found to differ with respect to reference group affiliation, technology schema, resistance to change, nature of social relations, perception of reality, and physical dexterity.

The authors found that when informants identified with particular referent groups including professional and social affiliations, the informants were likely to adopt the predominant group stance toward embracing or rejecting technology. Further, the informant's overall technology schema, an organized and arranged set of expectations and beliefs about technology, influenced the informant's inclination or aversion toward information technology. Users intimidated by technology in general were less willing to attempt interactions with information technology.

Trocchia and Swinder further found that an informant's general tendency to accept or reject change seemed to play a role in distinguishing users from non-users, with users generally displaying more tendencies to accept change than non-users. The nature of social relations was also found to differentiate users from non-users, where users typically enjoyed not only connecting with friends and family via electronic mail, but also making new acquaintances through chat rooms. Non-users found little value in these activities, commonly noting that they knew no one with email and so had no reason to use it.

Related to perception of reality, the authors found that individuals who valued personal and physical contact, for example, consumers needing to touch an actual physical item before purchasing it, were more likely non-users, while users typically were able to find adequate satisfaction with virtual representations. Finally, it was found that physical dexterity impairments could have a positive or negative impact on Internet usage, depending upon the type of affliction. The authors note that maladies such as arthritis and visual degeneration negatively impact Internet usage while many maladies which restrict physical movement positively impact Internet usage since it is easier for the afflicted to make purchases, engage in forms of entertainment, and communicate online from home than it is for them to venture into the physical world.

Andersson et al. (2002) discusses potential acceptance of information technology in terms of usability by adapting Nielsen's 1993 model, noting that usable products are those which match the user's needs and capabilities. To be usable, and therefore more likely accepted, a product should be visually pleasant and of direct interest to intended users; easily navigable; 
efficient, both in terms of ease of searching and response time; helpful in that it closely corresponds with users' expectations about its content and structure; and learnable with a minimum of instruction. The authors applied these principles to the development of an online informational service for the elderly and their family caregivers and found that older people are willing to use technology if it conforms to principles of usability, making it easy to learn, use, and understand.

Rubel (1995) also stresses the importance of usability. He notes that the needs of the mature market are sometimes misinterpreted, often because these consumers do not realize how much their abilities have changed and how much gradual adaptation has occurred. As a result, products developed to address mature consumers" "recognized" needs fall short because they do not address the existing needs for which some unconscious adaptation has occurred. Developing and marketing usable products which appeal to older consumers includes understanding the differences in human abilities and learning which abilities most affect successful use of the proposed product; creating new solutions based on universal design principles; testing products for usability, usefulness, and appeal with design-sensitive consumers; refining the product and selling the design, usefulness, benefits, and joy of use; and communicating the superior design of the product without telling people they have a need for it.

Bowe, as early as 1988 , found that older people are sometimes unwilling to face the changes that aging has brought and so avoid products that highlight these changes. He quotes Kermit Phelps, then chairman of the board of the American Association of Retired Persons (AARP) finding that older consumers "would prefer to put up with inconvenience and perhaps even occasional danger rather than use something that marks them as being old" (1988, p.36). Bowie stresses that one major challenge of companies dealing with the senior market is to overcome the difference factor: companies need to devise marketing strategies that covey the benefits of the product without giving the elderly the impression that the product will highlight their age and/or infirmities.

Although senior citizens may seem generally indifferent to engaging with information technologies such as personal computers and the Internet, the works of Trocchia and Swinder, Andersson et al., Rubel, and Bowe show that personal and technological factors do influence engagement potential. While some personal factors such as a negative technology schema, strong resistance to change, and a need to perceive reality through physical or personal contact may be so deeply ingrained that they create a near insurmountable barrier to potential engagement, the factors of reference group affiliation, nature of social relations, and physical dexterity are more changeable and so may be used to either aid or deter engagement. From a technological standpoint, a variety of factors exist which can be used to make information technology more usable and attractive to potential adopters. Key to potential engagement, though, is finding ways to present the attractiveness of information technology to elder consumers without making the user feel the technology targets age or infirmity.

\section{Implications}

Analysis of the various works presented in this paper regarding older peoples' interactions with information technology shows that many senior citizens are indifferent to engaging with information technology and the numbers of those who choose to engage increase very slowly. Because information technology usage can positively impact quality of life in terms of familial relationships, access to resources, and ensuring that quality of care does not decline due to a decreasing pool of caregivers, this current state of indifference creates some important sociological repercussions.

First, senior citizens, representing a large and growing segment of the population, may not be fully aware of resources available to optimize their standard of living. Brink finds that this decreased awareness may lead to four potential types of exclusion from society, all of which can negatively impact quality of life. These exclusions include lack of exposure or access to helpful goods and services, exclusion from use due to technological illiteracy, exclusion from use related to unsuitable design, and exclusion by cost. Taken together, these exclusions may have the effect of marginalizing older people from the information economy and from society.

Second, Lee and Geistfield (1999) note that the elderly are particularly susceptible to social isolation. Life events such as retirement, loss of spouse, and children leaving home reduce opportunities for social interaction. Social isolation may cause depression, increase the likelihood of disengagement from life, and even lead to increased potential for crimes targeting seniors such as fraud and undue influence. Online seniors often feel more 
connected to family and friends through use of email and chatrooms. Pew (2001) noted that 56 percent of online seniors found that their use of the Internet led to improved relations with family. Clearly, information technology usage can help to combat feelings of social isolation.

Finally, senior citizens are often disproportionately targeted for financial crime due to factors such as social isolation, a willingness to trust others, relative naïveté of potential confidence schemes, and a perception of large reserves of retirement savings. The Federal Bureau of Investigation (FBI) estimates there are 14,000 fraudulent telemarketing firms operating in the United States, with $80 \%$ directing their activities at older people (Lee \& Geistfield, 1999). When the Federal Trade Commission (FTC) brought fraud charges against telemarketing companies that solicited charitable contributions in return for a prize, $85 \%$ of the victims were 65 years of age or older (Pitofsky, as cited in Lee \& Geistfield, 1999). In many of these crimes, the ability of the perpetrator to collect and use personal information about the victim is a key element of the crime. Personal information is more readily accessible than ever due to the impact of information technology, but Hough found that senior citizens are only moderately aware of potential misuse of this information and so face significant susceptibility for victimization.

In addition to the sociological repercussions of seniors who are relatively disengaged with respect to information technology, there may be significant commercial opportunities related to providing opportunities for engagement. The usage statistics presented throughout this paper provide compelling evidence that there is a tremendous untapped market of seniors who do not interact with higher information technologies such as personal computing and the Internet.

Although a significant portion of these seniors indicate they do not ever intend to engage, and certain deeply engrained personality characteristics make engagement unlikely, there is still a large pool of older people who might be encouraged to engage, given the right conditions. Factors such as group affiliation, social relationships, comfort with virtual representations, dexterity needs, usable design, and clever presentation may contribute to creating an atmosphere conducive to engagement.

Additionally, Strutton, Lumpkin, and Vitell (1994) found that elder consumers display different perceptual patterns of evaluation of potential innovations according to whether the consumer believes the innovation is an incremental improvement of an existing product or an entirely new type of innovation. For those innovations perceived to be entirely new, the elder consumers considered a far greater number of innovation characteristics before adoption, placing new innovations under more intense scrutiny than those innovations perceived to be improvements of existing products. As such, marketers of information technology might achieve better penetration by use of analogy to portray the similarities of higher technologies to their more frequently used lower technology counterparts.

The population of the United States will continue to include an ever-increasing number of senior citizens with longer life expectancies. The current cohort of senior citizens are relatively indifferent regarding engagement with information technology, even though engagement can provide significant benefits, enhance quality of life, and reduce potential victimization from financial crimes. Although the upcoming cohort of elderly, the silver tsunami, is far more immersed in information technology and may experience a better quality of life as a result, the lack of interaction of the current cohort cannot be viewed as a short-term phenomenon since life expectancies continue to increase. Finding ways to engage seniors with respect to information technology is of critical importance and will benefit the elderly, their caregivers, providers of information technology goods and services, and society in general.

\section{Suggestions for Future Research}

Efforts to date to engage older people with respect to information technology have been somewhat successful when family relationships are used to provide encouragement. Little evidence exists to illustrate the success of outsider efforts in encouraging engagement. Although most seniors indicate they interact with traditional forms of information technology such as telephone, television, newspapers, credit, debit, and affinity cards, the numbers of seniors who engage in personal computing and the Internet are slow to increase. Since increased engagement has significant societal and commercial implications, future research should focus on determining what factors can be used to create an atmosphere conducive to senior interaction with higher information technologies. 
In creation of this conducive atmosphere, attention should be given to developing marketing models which portray the benefits of interaction without focusing on age and infirmity. Further, additional research in usability would be beneficial so that hardware, software, and interfaces are tailored and optimized toward a senior audience.

\section{References}

1. Andersson, N., Hanson, E., \& Magnusson, L. (2002). Views of family carers and older people of information technology. British Journal of Nursing, 11(12), 827-831.

2. Bowe, F. (1988). Why seniors don't use technology. Technology Review, August/September. 34-40.

3. Brink, S. (1997). The twin challenges of information technology and population aging. Generations, 21(3), 7-10.

4. Coughlin, J. F. (1999). Technology needs of aging boomers. Issues in Science and Technology, 16, 53-60.

5. Fox, S. (2001). Wired seniors. Pew Internet \& American Life Project. [On-line]. Available: www.pewinternet.org.

6. Fox, S. (2004). Older Americans and the Internet. Pew Internet \& American Life Project. [On-line]. Available: www.pewinternet.org.

7. Horrigan, J. (2003). Consumption of information goods and services in the United States. Pew

8. $\quad$ Internet \& American Life Project. [On-line]. Available: www.pewinternet.org.

9. Hough, M. (2002). Evaluating and enhancing senior citizen awareness of the effect of technology on privacy. (Doctoral dissertation, Robert Morris University, Pittsburgh, 2002). University Microfilms International.

10. Lee, J. \& Geistfield, L. (1999). Elder consumer's receptiveness to telemarketing fraud. Journal of Public Policy \& Marketing, 18, 208-217.

11. Longino, C. (1994). Myths of an aging America. American Demographics, 16(8), 36-42.

12. Mann, W. (1997). Common telecommunications technology for promoting safety, independence, and social interaction for older people with disabilities. Generations, 21(3), 28-29.

13. Rubel, C. (1995). Mature market often misunderstood. Marketing News, 29(18), 28-29.

14. Strutton, H., Lumpkin, J., \& Vitell, S. (1994). An applied investigation of Rogers and Shoemaker's perceived innovation attribute typology when marketing to elderly consumers. Journal of Applied Business Research, 10(1), 118-131.

15. Titus, E. (1982). A comparative study of the learning outcomes of senior citizens in assertiveness training provided by professional trainers and trained peer volunteers. (Doctoral dissertation, University of Wyoming, Laramie, 1982). University Microfilms International.

16. Trocchia, P., \& Swinder, J. (2000). A phenomenological investigation of Internet usage among older individuals. The Journal of Consumer Marketing, 17(7), 605-612. 